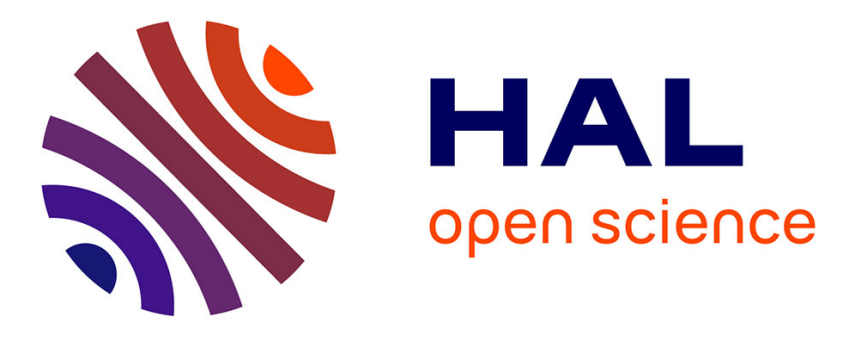

\title{
Influence of SLM process parameters on the surface finish, porosity rate and fatigue behavior of as-built Inconel 625 parts
}

Imade Koutiri, Etienne Pessard, Patrice Peyre, Ouafae Amlou, Thibaut de Terris

\section{To cite this version:}

Imade Koutiri, Etienne Pessard, Patrice Peyre, Ouafae Amlou, Thibaut de Terris. Influence of SLM process parameters on the surface finish, porosity rate and fatigue behavior of asbuilt Inconel 625 parts. Journal of Materials Processing Technology, 2018, 255, pp.536-546. 10.1016/j.jmatprotec.2017.12.043 . hal-01826611

\section{HAL Id: hal-01826611 https://hal.science/hal-01826611}

Submitted on 29 Jun 2018

HAL is a multi-disciplinary open access archive for the deposit and dissemination of scientific research documents, whether they are published or not. The documents may come from teaching and research institutions in France or abroad, or from public or private research centers.
L'archive ouverte pluridisciplinaire HAL, est destinée au dépôt et à la diffusion de documents scientifiques de niveau recherche, publiés ou non, émanant des établissements d'enseignement et de recherche français ou étrangers, des laboratoires publics ou privés. 


\title{
Influence of SLM process parameters on the surface finish, porosity rate and fatigue behavior of as-built Inconel 625 parts
}

\author{
Imade Koutiri $^{\mathrm{a}, *}$, Etienne Pessard ${ }^{\mathrm{b}}$, Patrice Peyre ${ }^{\mathrm{a}}$, Ouafae Amlou ${ }^{\mathrm{a}}$, Thibaut De Terris ${ }^{\mathrm{a}}$ \\ a Arts et Métiers ParisTech, CER Paris-Laboratoire PIMM - UMR 8006 CNRS - ENSAM - CNAM, 151 Bd de l'hôpital, 75013 Paris, France \\ ${ }^{\mathrm{b}}$ Arts et Métiers ParisTech, CER Angers - Laboratoire LAMPA - 2 Bd du Ronceray, 49035 Angers Cedex 1, France
}

\section{A R T I C L E I N F O}

\section{Keywords:}

SLM

Particle

Fatigue

Inconel 625

Porosity

Surface finish

\begin{abstract}
A B S T R A C T
This paper is dedicated to understanding fatigue crack initiation for an Inconel 625 manufactured by SLM, using a hatching + contour procedure. In the first part of the paper, an optimum set of parameters was found to deliver the best surface roughness combined with low porosity. This process optimization, mostly focused on adjusting the volume energy density aimed at finding a compromise between an optimum densification state and a minimum number of contaminating spatters. Secondly, a fatigue test campaign has been conducted on as-built SLM samples or polished samples. The analysis of failure surfaces allowed identifying different heterogeneities at the origin of the fatigue damage for each configuration. The embedded particles on the surface of as-build specimens have been shown to play an important role in fatigue and need to be optimized or taken into account in the fatigue strength design of SLM components.
\end{abstract}

\section{Introduction}

Additive Layer Manufacturing (ALM) currently impacts several industrial sectors, ranging from medical to aerospace and energy. Since 2003, there has been a $42 \%$ increase of parts produced by additive manufacturing. ALM processes, generating mechanical parts layer by layer, allow realizing complex shapes which are not achievable by traditional processes at significantly reduced cost. A limitation for the development of this process is still considered to be the mechanical properties obtained of as-built ALM parts, and the possible occurrence of defects, allowing the direct use-or not- of these parts in an industrial environment.

Static properties of ALM materials have been the subject of a tremendous number of works in the past 3 years, and it has been shown that ALM alloys could exhibit correct static mechanical resistance compared to wrought or cast alloys. For instance, Chastanda et al. (2016) show that fatigue properties of Titanium Ti6Al4V parts built by SLM are comparable to casting after stress relieving and comparable to wrought processes after an HIP heat treatment.

The durability of ALM parts has become an important topic to address for many applications, fatigue failure of materials being one of the most common damage modes in cyclically loaded metallic materials. Many works have resulted in a better knowledge of the phenomena involved. These studies contributed to a better understanding of the mechanisms of crack initiation involved on ALM materials and proposed new models to predict the material fatigue behavior.

In many papers, it appears that high cycle fatigue cracks, for part with as-built surface, usually initiate on:

- porosities on the surface or sub-surface, generated by ALM process for different materials like Ti6AL4V (Ellyson et al., 2017), AlSi10Mg (Brandl et al., 2012), AlSI12 for very high cycle fatigue (Siddique et al., 2017) and 630 stainless steel (Akita et al., 2016). Such subsurface porosities are mostly located in the transition zone between contour path and hatching path.

- Elevated surface roughness, especially on inclined parts, that tends to generate stress concentration factors and favor crack's initiation.

- Un-melted particles located close to the surface of specimens. Such particles have been observed already on a Ti6AL4V (Fatemi et al., 2017) and on a AlSi10Mg (Brandl et al., 2012).

Following this last statement, one of the well-known issues in SLM is the contamination of the powder bed surface by large spatters (Khairallah et al., 2016) generated during laser - powder bed - meltpool interaction. The generation of such spatters is usually favored by high volume energy densities VED = P/ (S. V) (high power P, low scan velocity $\mathrm{V}$, small laser-irradiated surface $\mathrm{S}$ ) that tend to destabilize melt-pools and surrounding powder beds. However, it is also well known that high VED values are required to obtain an optimum densification state. For this reason, and because a compromise is hard to

\footnotetext{
* Corresponding author.

E-mail address: imade.koutiri@ensam.eu (I. Koutiri).
} 
find, most of SLM parts are systematically submitted to post-machining steps (sand blasting, electro-polishing, grinding) to improve surface finish. Such machining steps are not easy to carry out on complex shapes, and in some specific cases, as-built SLM samples can be envisaged for parts submitted to reduced static or cyclic loading. Consequently, mechanical investigations on as-built samples are still of importance.

The current study focuses mainly on the effects of material's heterogeneities (surface roughness and porosity) generated in an Inconel 625 part by the SLM process. In a first step, process parameters such as laser power $\mathrm{P}$, beam diameter $\mathrm{D}$, scanning speed $\mathrm{V}$ and orientation angle $\theta$ of the piece versus the building platform will be varied in order to optimize surface roughness and porosity rate (considered as the percentage of void spaces in a material over the total volume). In a second step, as-built specimens manufactured with optimum SLM conditions will be submitted to cyclic loading in order to evaluate fatigue limits and to detect the origin of the crack initiation.

\section{Experimental procedure: Inconel 625 and SLM conditions}

Selective Laser Melting (SLM) is one of the two powder bed method (with EBM) for the additive manufacturing of metallic alloys. It allows the processing of a large range of metals including Ni-based alloys, stainless steels, cobalt-chromium, aluminum and titanium alloys.

\subsection{Inconel 625}

A wide range of Ni-based superalloys, like Inconel 718, Nimonic 623 has been manufactured already with additive layer process, including Inconel 625. This nickel based superalloy is widely used in applications like supercritical water reactors or engine with high temperatures. It combines high mechanical properties with good corrosion resistance due to its high $\mathrm{Cr}$ content. Nickel is the principal element of this alloy and the principal constituent of the austenitic matrix $\gamma$. Ni participates also in the composition of secondary phases $\left(\gamma^{\prime}, \gamma^{\prime \prime}\right.$ and $\delta$ ) and gives to the material a good resistance on a large range of temperature (from cryogenic temperatures to $900^{\circ} \mathrm{C}$ ).

The following table summarizes literatures data for mechanical properties of Inconel 625 in a wrought or SLM state (for horizontal and vertical direction). Our results and literature data show a variability in the mechanical properties (especially in elongation rate) depending on the set of process parameters and the building direction.

The Inconel 625 powder, obtained by inert gas atomization, was supplied by PRAXAIR with a $10-45 \mu \mathrm{m}$ particle range. This particle distribution was confirmed by a laser granulometer device (CILAS) as shown in Fig. 1. The particle shape has also been observed by Scanning Electron Microscopy (SEM). Particles present a mostly spherical shape with no satellites (Fig. 1), and no agglomeration.
Prior to SLM, the powder was systematically heated for $24 \mathrm{~h}$ at $50{ }^{\circ} \mathrm{C}$ in order to remove the residual moisture adsorbed on particles. This heating stage allows improving the powder spreading in order to have homogeneous powder layers.

\subsection{SLM conditions}

All the specimens investigated in this study are manufactured by a SLM 125HL machine provided by the SLM Solutions GmbH company. In the first part of the study, we will vary the irradiation parameters: laser power $\mathrm{P}$ (between 100 and $400 \mathrm{~W})$, scanning velocity $\mathrm{V}(0.5-1.8 \mathrm{~m} / \mathrm{s})$, beam diameter $\mathrm{D}(70-160 \mu \mathrm{m})$, for both the contour and hatching parameters (Table 2). A specific focus will also be given to the influence of tilt angle $\theta\left(0^{\circ}\right.$ to $\left.35^{\circ}\right)$ between the platform and the part. The other process parameters (hatch distance, hatching strategy $=$ stripes ...) will be fixed and will not be considered. The objective of this optimization step is to obtain parts with the best surface roughness and the lower porosity ratio, which are both known to promote fatigue crack initiation. In this first stage, dedicated to the parametric study, only blocks of $10 \times 18 \times 4 \mathrm{~mm}$ were manufactured. For each set of parameters, a volume energy density (VED) has been calculated using Eq. (1). Such an equation allows considering the amount of energy induced by the laser scanning on the powder bed as an unified process parameter. This specific analytical formulation of laser energy input VED can be directly correlated to penetration depths of beads as shown analytically by (Fabbro et al., 2017) and confirmed experimentally in (Gunenthiram et al., 2018).

$\operatorname{VED}\left(J / \mathrm{m}^{3}\right)=P(W) / V(\mathrm{~m} / \mathrm{s}) . A\left(m^{2}\right)$

With $A=$ spot area $\left(\pi . D^{2} / 4\right)$

All the process parameters (Contour and hatching parameters) are reported in Table 2.

The second part of the study is dedicated to the production of tensile and fatigue samples (Fig. 2), using optimized process parameters (P, V, D). The geometry of tensile and fatigue specimens are shown in Fig. 3. A rounded edge was carried out to avoid local fatigue crack initiation.

\section{Influence of SLM parameters on surface finish}

\subsection{Influence of laser power (contour stage) and building angle}

All the samples were characterized using a VEECO Dektak 150 profilometer, using a $12 \mu \mathrm{m}$ curvature radius stylus and a $1 \mathrm{mg}$ weight to scan the surfaces. The measurement technique is based on contact stylus profilometry. The non-filtered surface finish values Sa presented here below (Table 2) are the mean values of three scan surfaces of $1 \times 1 \mathrm{~mm}$.

We first focus here on the effect of the tilt angle and contour laser
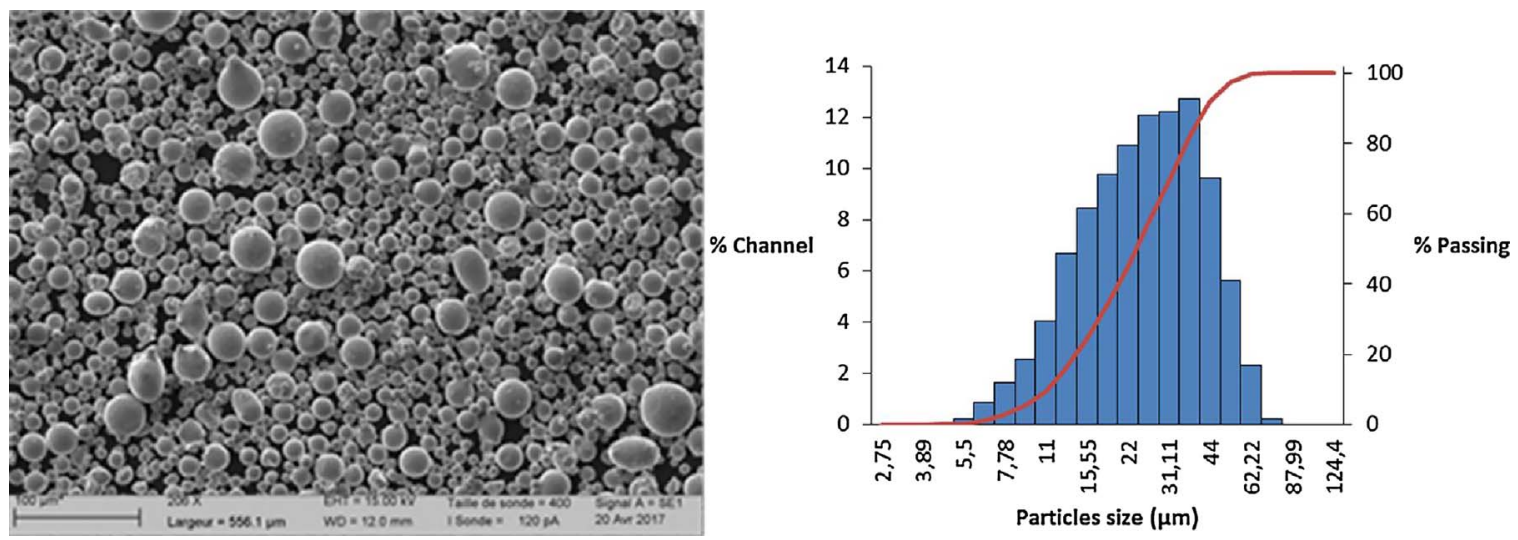

Fig. 1. (a) SEM analysis of powder particles, (b) Inconel 625 Grain distribution. 
Table 1

Mechanical properties of Inconel 625 (Literature data)

\begin{tabular}{|c|c|c|c|c|c|c|c|}
\hline Ref. & Process & UTS (MPa) & Yield strength (MPa) & Elongation (\%) & $\mathrm{P}(\mathrm{W})$ & $\mathrm{V}(\mathrm{m} / \mathrm{s})$ & Powder thickness $(\mu \mathrm{m})$ \\
\hline (Yadroitsev et al., 2007) & Wrought Inconel 625 & 930 & 517 & 40 & & & \\
\hline (Yadroitsev et al., 2007) & SLM Horizontal samples & 1030 & 800 & $8-10$ & 50 & 0.13 & 50 \\
\hline (Yadroitsev et al., 2007) & SLM Vertical samples & 1070 & 720 & $8-10$ & 50 & 0.13 & 50 \\
\hline (Wang et al., 2016) & SLM Horizontal samples & 878 & 641 & 30 & 360 & 0.4 & 50 \\
\hline
\end{tabular}

Table 2

Process parameters (laser power, scan speed, spot diameter and tilt angle) and resulting surface finish

\begin{tabular}{|c|c|c|c|c|c|c|c|c|c|c|}
\hline \multicolumn{2}{|l|}{ Number of specimen } & \multirow[t]{2}{*}{$\theta\left({ }^{\circ}\right)$} & \multicolumn{3}{|c|}{ Contour parameters } & \multirow{2}{*}{$\begin{array}{l}\text { VED (contour)) } \\
\mathrm{J} / \mathrm{mm}^{3}\end{array}$} & \multicolumn{3}{|c|}{ Hatching parameters } & \multirow{2}{*}{$\begin{array}{l}\text { Roughness* } \\
\text { Sa }(\mu \mathrm{m})\end{array}$} \\
\hline & & & $\mathrm{P}(\mathrm{W})$ & $\mathrm{V}(\mathrm{m} / \mathrm{s})$ & $\mathrm{D}(\mu \mathrm{m})$ & & $\mathrm{P}(\mathrm{W})$ & $\mathrm{V}(\mathrm{m} / \mathrm{s})$ & $\mathrm{D}(\mu \mathrm{m})$ & \\
\hline \multirow{16}{*}{ Tests for Surface roughness } & 1 & 10 & 100 & 0.5 & 70 & 52 & 175 & 0.6 & 70 & $11 / 14$ \\
\hline & 2 & 10 & 140 & 0.5 & 70 & 72.8 & 175 & 0.6 & 70 & $7.5 / 11.8$ \\
\hline & 3 & 10 & 180 & 0.5 & 70 & 93.6 & 175 & 0.6 & 70 & $5.9 / 6.2$ \\
\hline & 4 & 35 & 100 & 0.5 & 70 & 52 & 175 & 0.6 & 70 & $11 / 16.5$ \\
\hline & 5 & 35 & 140 & 0.5 & 70 & 72.8 & 175 & 0.6 & 70 & $7.5 / 20.5$ \\
\hline & 6 & 35 & 180 & 0.5 & 70 & 93.6 & 175 & 0.6 & 70 & $10.6 / 23$ \\
\hline & 7 & 0 & 400 & 1 & 70 & 104 & 400 & 1 & 70 & 10.5 \\
\hline & 8 & 0 & 400 & 1.4 & 70 & 74.3 & 400 & 1.4 & 70 & 12.3 \\
\hline & 9 & 0 & 400 & 1.8 & 70 & 57.8 & 400 & 1.8 & 70 & 12.4 \\
\hline & 10 & 0 & 400 & 2 & 70 & 52 & 400 & 2 & 70 & 9.5 \\
\hline & 11 & 0 & 400 & 1 & 160 & 19.9 & 400 & 1 & 160 & 21 \\
\hline & 12 & 0 & 400 & 1.4 & 160 & 14.2 & 400 & 1.4 & 160 & 18.9 \\
\hline & 13 & 0 & 400 & 1.8 & 160 & 11.1 & 400 & 1.8 & 160 & 17.1 \\
\hline & 14 & 0 & 400 & 2 & 160 & 10 & 400 & 2 & 160 & 15.2 \\
\hline & 15 & 0 & 400 & 1 & 240 & 8.8 & 400 & 1 & 240 & 21 \\
\hline & 16 & 0 & 400 & 1.4 & 240 & 6.3 & 400 & 1.4 & 240 & 20.3 \\
\hline
\end{tabular}

( $*$ bold $=$ upper surface, normal $=$ lower surface $).$

power on the surface roughness, at constant beam diameter $(70 \mu \mathrm{m})$ (samples 1-6). Even if the hatching stage is also known to affect surface roughness by varying the average temperature of parts, only contour parameters have been addressed whereas hatching parameters have been kept constant $(\mathrm{P}=175 \mathrm{~W}$ and $\mathrm{V}=0.6 \mathrm{~m} / \mathrm{s})$. Two tilt angles $\theta\left(10^{\circ}\right.$ and $\left.35^{\circ}\right)$ and three laser powers $(100,140$ and $180 \mathrm{~W})$ have been tested. $35^{\circ}$ was selected as the threshold angle above which supporting is usually required in SLM, due to heat accumulation in bottom sides (because of the low conductivity of powder bed). The scanning velocity is fixed and equal to $0.6 \mathrm{~m} / \mathrm{s}$. Finally, six blocks (specimen 1-6), presented in Table 2 have been obtained. For specimen 1-6, the VED values are related only to contour parameters contrary to the other specimens.

Results are presented in Figs. 4 and 5 considering Sa average roughness, which measures the arithmetic average deviation of the nonfiltered measured profile from the centerline of the measured profile. Globally, $S_{a}$ values are comprised between 6 and $11 \mu \mathrm{m}$ and tend to decrease with heat input (=laser power), indicating a smoothing effect, except for the $35^{\circ}$ angle, for which specific boundary conditions (lower heat dissipation) tend to provoke a roughness increase between $140 \mathrm{~W}$ and $180 \mathrm{~W}$ (Fig. 4). This result confirms afterwards that supporting is mandatory above $\theta=35^{\circ}$ to favour heat dissipation and limit

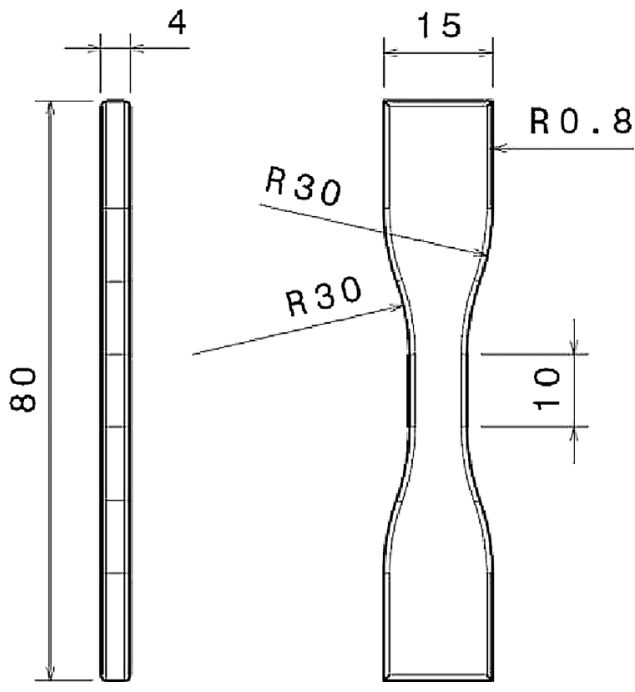

Fig. 3. Geometry of the specimens tested in fatigue.
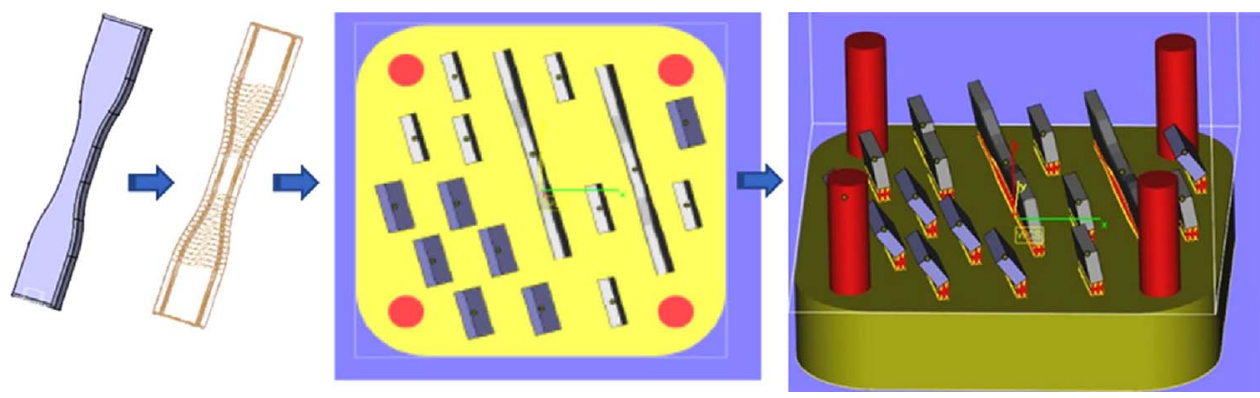

Fig. 2. Workflow of the SLM pre-processing. 


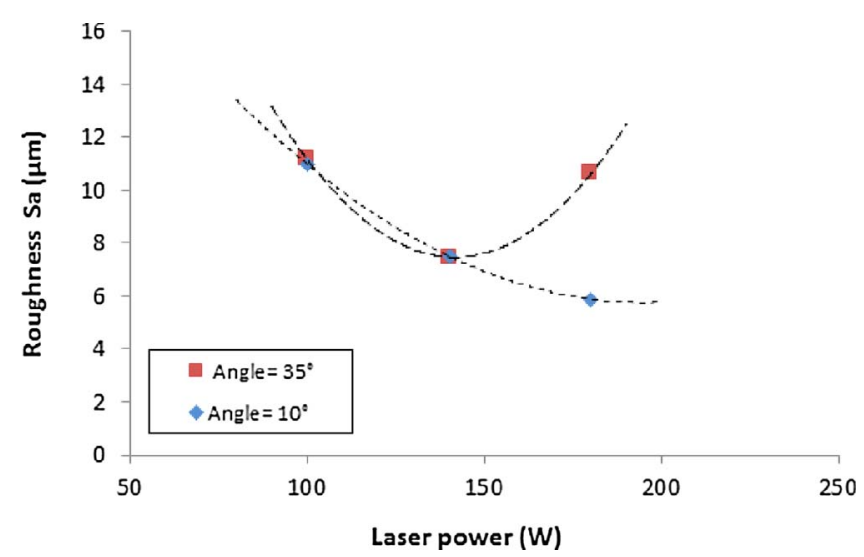

Fig. 4. Sa Roughness vs Laser Power for a tilt angle equal to $10^{\circ}$ and $35^{\circ}$ (upper surface) and a scan speed of $0.5 \mathrm{~m} / \mathrm{s}$.

deleterious surface finish.

As shown in Fig. 5, even for low building angles $\left(\theta=10^{\circ}\right)$ a roughness difference is systematically found between top and bottom sides of the specimen. (Leary, 2017) and (Triantaphyllou et al., 2015) observed the same behaviour in a Ti6Al4V. This indicates different temperature ranges between up and bottom sides, whatever the building angle. These first results confirm that both the angle between the platform and the part and the laser power influence the surface roughness, which can be modified by a factor 2 depending on process parameters. To explain these results, it can be assumed that the influence of laser power is two-fold: on the one hand, higher powers tend to favour layer re-melting and provoke a smoothing effect, and on the other hand excessive laser powers, combined with large angles $\theta$ favour sticking of surrounding particles on overhanging parts in the powder bed (Fig. 6).

3D scans corresponding to six tests presented in Fig. 4 confirm the results already presented.
- For $\theta=10^{\circ}$, a decrease of the surface ratio of large "red" agglomerates on the surface with laser power is obtained. Such agglomerates disappear for $\mathrm{P}=180 \mathrm{~W}$.

- For $\theta=35^{\circ}$, large agglomerates decrease between 100 and $140 \mathrm{~W}$ then increase-again for $\mathrm{P}=180 \mathrm{~W}$.

This confirms that an increase of laser power tends to increase the size of the melted area, allowing a better re-melting of previous layers and a better spreading of large particles stuck and incrusted onto the surface $\left(\theta=10^{\circ}\right)$. Therefore, the quantity of agglomerated powder decreases, which improves the surface roughness. Such macro-agglomerates can mostly be attributed to the combination of two factors: (1) liquid spatters formed during laser-powder-melt-pool interaction, which tend to increase with VED values and contaminate powder beds and manufactured parts, or (2) to the surrounding powder bed where powder grains located in the close vicinity of the fused walls can coalesce, grow and stick onto the surface. Those incrusted particles are susceptible to play a dominant role during the cyclic tests and favor fatigue crack initiations as they are fully embedded in the surface as shown in Fig. 7.

\subsection{Influence of contour scan speed and beam diameter}

In a second stage, we addressed the effect of scanning velocity and focus diameter of the contour phases on the resulting surface roughness considering a unique building angle $\theta=0^{\circ}$. The objective was to check if the use of a single and unified energy parameter, including $\mathrm{P}, \mathrm{V}$, and $\mathrm{D}$ was sufficient to represent roughness variations. For these specific trials (samples 7-16 in Table 2), the laser power was increased and set constant to $400 \mathrm{~W}$, the maximum available laser power of our SLM machine. Three beam diameters $(70,160$ and $240 \mu \mathrm{m})$, plus four scanning velocities $(1,1.4,1.8$ and $2 \mathrm{~m} / \mathrm{s})$ were tested. With such conditions, the VED range was larger than previously used with a $100-180 \mathrm{~W}$ laser power, and similar contour / hatching process parameters were used.

At $\mathrm{P}=400 \mathrm{~W}$, one can observe (Fig. 8):

(b) upper side
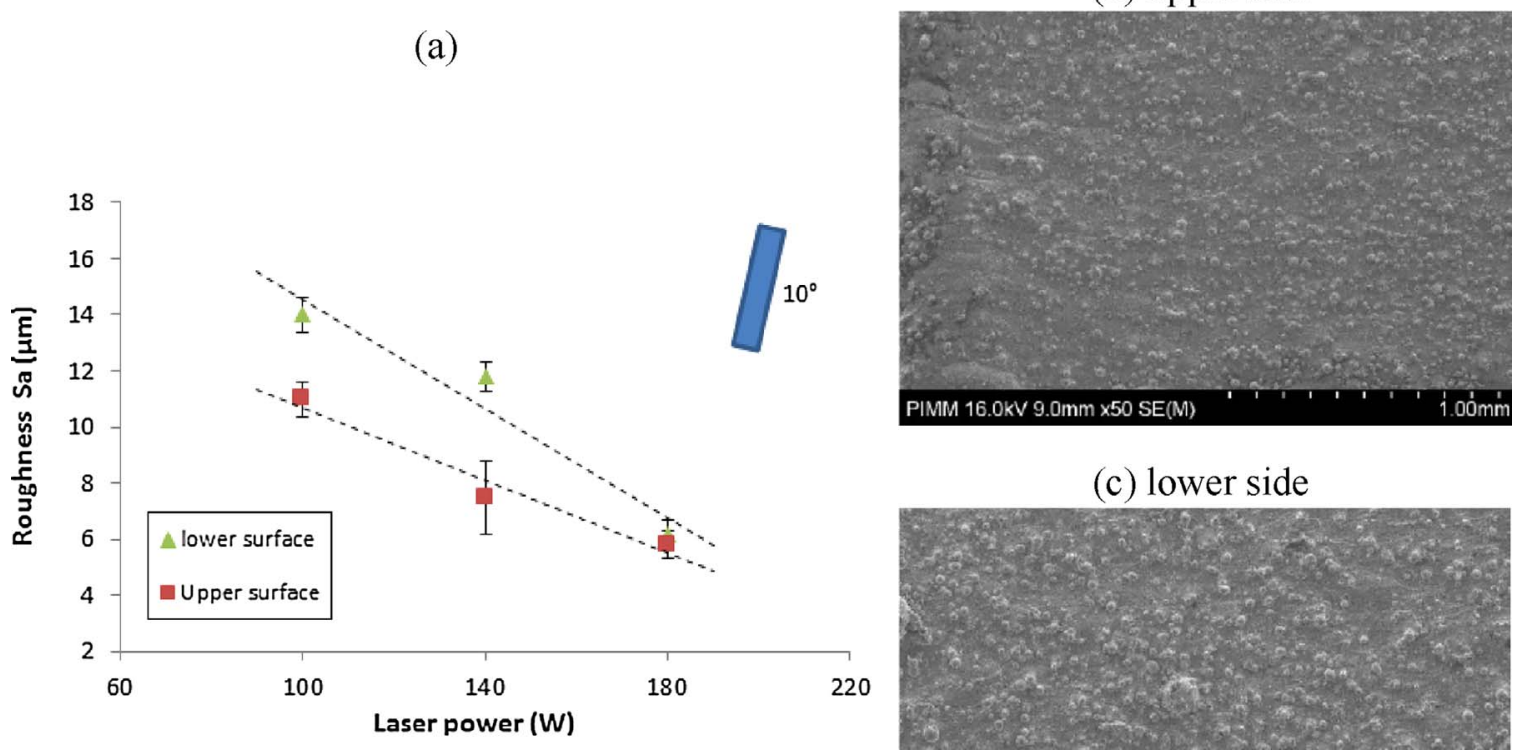

(c) lower side

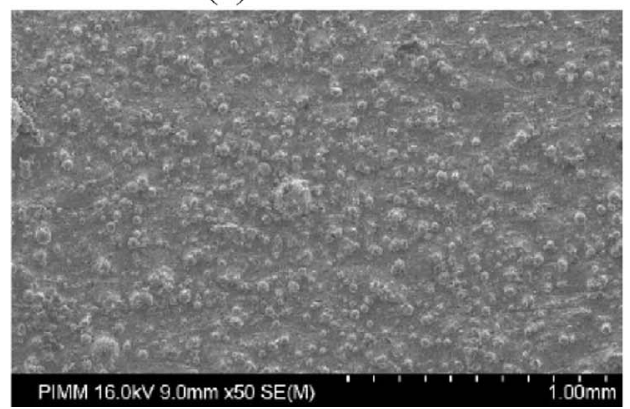

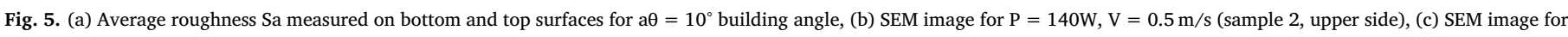
sample 2 (lower side). 


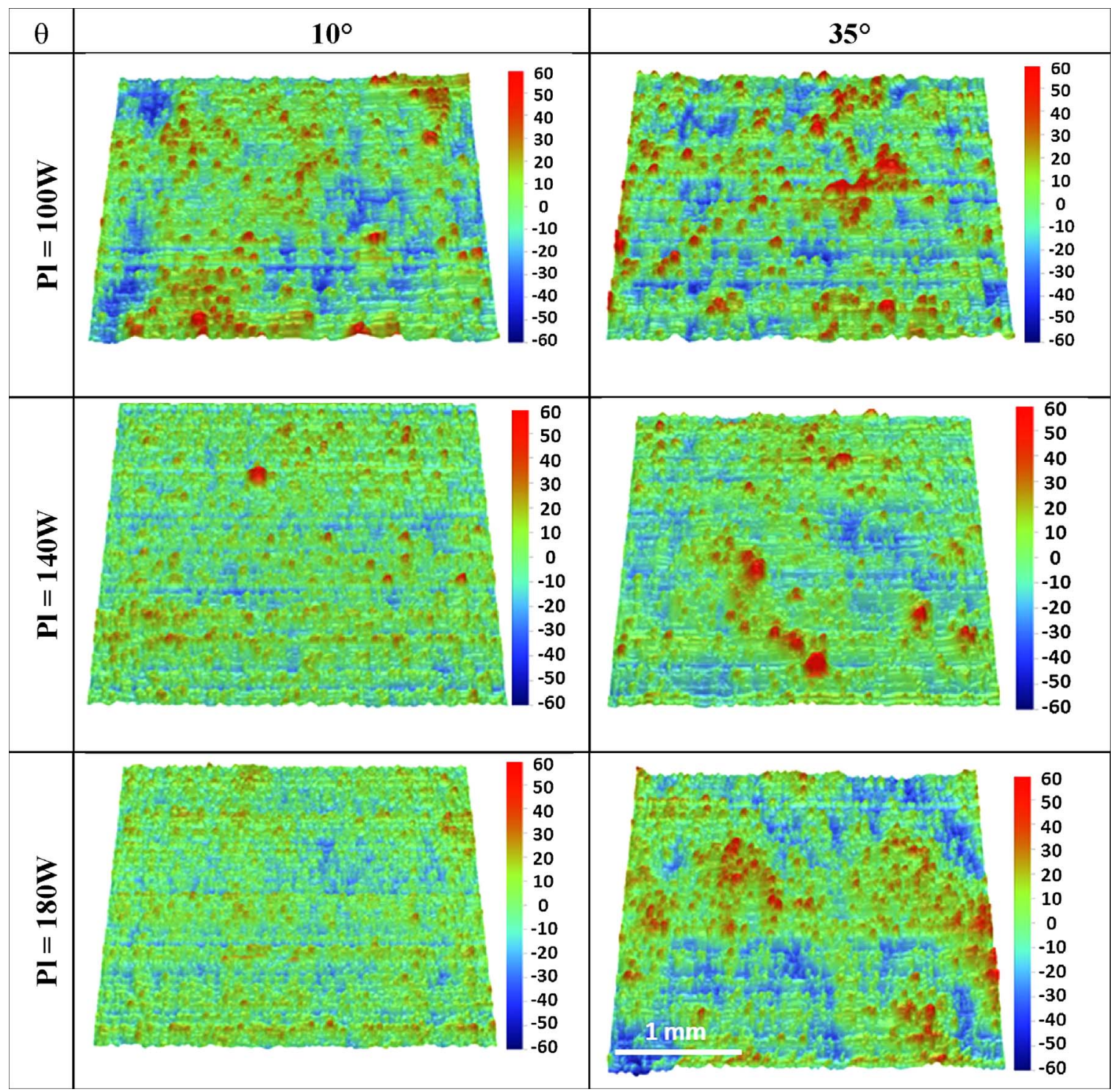

Fig. 6. 3D maps $(2.5 \mathrm{~mm} \times 3 \mathrm{~mm})$ of the SLM surfaces for $\mathrm{P}=100,140,180 \mathrm{~W}$ and $\theta=10,35^{\circ}$ (top surfaces) $(\mathrm{V}=0.6 \mathrm{~m} / \mathrm{s}$ ).
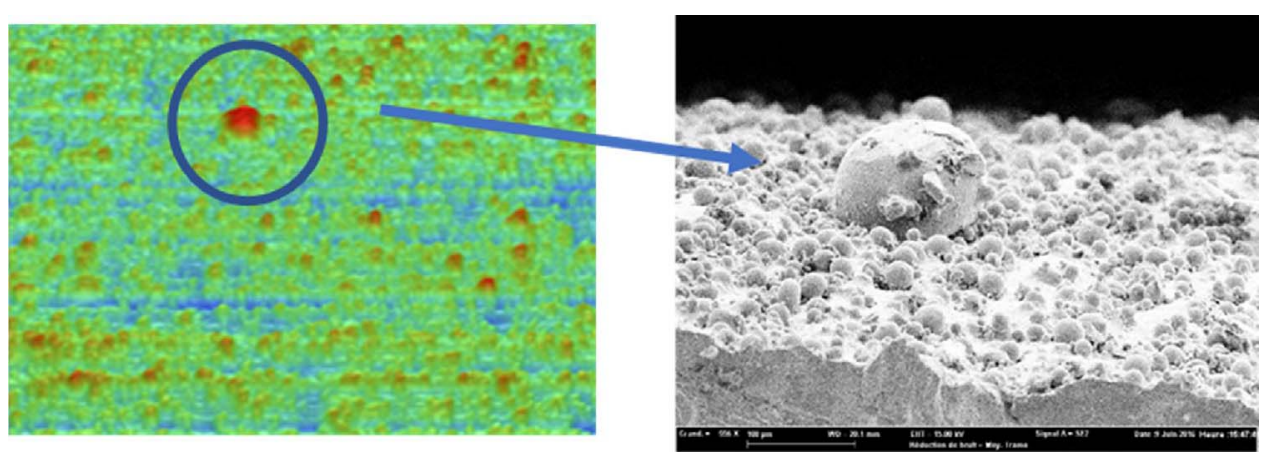

Fig. 7. Non-melted particle $(\mathrm{D} \approx 100 \mu \mathrm{m})$ on a SLM surface (a) 3D scan and (b) SEM image.

\section{- A global decrease of Sa with VED, indicating that high energy contour conditions promote surface smoothing.}

- An increase of the surface roughness value with the increase of the beam diameter.

- For a constant beam diameter, an increase of Sa with the decrease of scan velocity. However, for the low and high beam diameter value ( $D=70 \mu \mathrm{m}$ and $\mathrm{D}=240 \mu \mathrm{m}$ ), the variation of surface roughness is low, whereas for $\mathrm{D}=160 \mu \mathrm{m}$, a clear increase of surface roughness is shown with an increase of the energy density, coming from a scan velocity decrease.

Even if a clear smoothing effect is globally obtained with an increase of VED, if we consider similar building angles $\left(\approx 0-10^{\circ}\right)$, beam diameters $(70 \mu \mathrm{m})$ and VED values $\left(75-100 \mathrm{~J} / \mathrm{mm}^{3}\right)$, better surface finishes are obtained for $\mathrm{P}=140-180 \mathrm{~W}$ than for $\mathrm{P}=400 \mathrm{~W}$ (samples 2,3 with Ra 6-7 $\mu \mathrm{m}$ versus samples 7,8 with $\mathrm{Ra}=10-12 \mu \mathrm{m}$ in Table 2). This is 


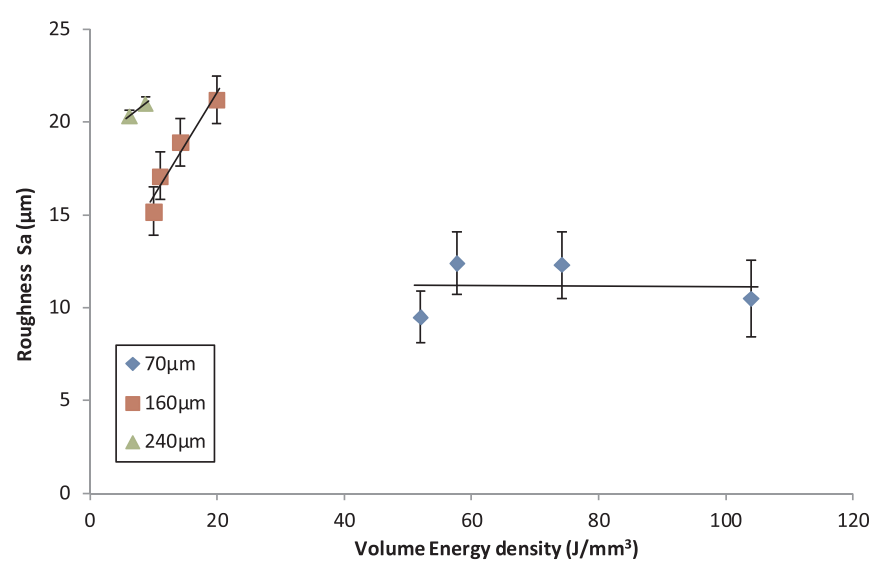

Fig. 8. Effect of beam diameter on the Sa parameter $\left(P=400 \mathrm{~W}\right.$, contour strategy, $0^{\circ}$ angle).

assumed to be due to an increase of spattering effect for $\mathrm{P}=400 \mathrm{~W}$.

The clear difference evidenced between surface finishes obtained with similar VED (for specimens 11-16 with VED between 6-20 J/ $\mathrm{mm} 3$ ) but different beam diameters mostly indicate that VED values are not sufficient to represent correctly the influence of SLM parameters on surface finish. Sa results presented here above mostly traduce the influence of scan speed at constant laser power: lower scan speed promote large but turbulent melt-pools which deteriorate surface finish, by increasing the amount of agglomerated spatters particles on the built surfaces (Khairallah et al., 2016).

Finally, such results clearly show that the correlation between surface roughness, which depends mostly on surface temperatures achieved on SLM part, and process parameters, is not a simple task, and that the use of VED as a representative factor is not fully satisfactory, when considering a large range of laser spot diameters. This could be attributed to a balance between the density of spatters contaminating SLM surfaces, which tend to increase with smaller scan speeds (at constant beam diameters) and to the global surface smoothing effect with smaller spot-diameters.

\section{Influence of hatching process parameters on porosity rate}

The second part of this study addresses the variation of porosity rate with hatching parameters, with the objective to minimize the void fraction, porosity being one of the microstructural heterogeneity which can initiate a fatigue crack. Various hatching parameters were used (Laser power, scanning velocity and angle of building), while keeping constant contour parameters $(\mathrm{P}=140 \mathrm{~W}, \mathrm{~V}=0.5 \mathrm{~m} / \mathrm{s})$.

According to previous works (Spierings et al., 2011), different techniques can be used for measuring densities on additive manufactured metallic parts: Archimedes' method, microscopic analysis of cross-sections and X-ray scanning, with up to $1 \%$ gap at elevated porosity rate.

Provided that wetting of metallic surfaces in the selected liquid is optimized, the Archimedes method is supposed to deliver more reliable and more global results as the whole sample volume is taken into account instead of some single cross sections. Moreover, this method is very easy to use, fast and cheap. Based on these results, density measurements have been carried out with the Archimedes' double weighing method to measure the density of parts. The basic principle consists of measuring the mass in normal air and in the fluid (water in the current paper). In the present configuration, the measuring accuracy of the Mettler Toledo MS104TS balance is $0.0001 \mathrm{~g}$.

The following equation allows the calculation of the density $\rho_{p}$ of the part:

$\rho_{p}=\frac{m_{a}}{m_{a}-m_{f l}} \cdot\left(\rho_{f l}-\rho_{a}\right)+\rho_{a}$

With $\mathrm{m}_{\mathrm{a}}=$ mass in the air, $\mathrm{m}_{\mathrm{fl}}$ mass in the fluid, $\rho_{\mathrm{a}}=$ air density, $\rho_{\mathrm{fl}}=$ fluid density

In the current study, we have investigated the possible link between porosity rate and volume energy density. Eight conditions have been tested including various hatching parameters (Laser power, scan velocity) (Table 3).

Two building angles $\left(10^{\circ}\right.$ and $\left.35^{\circ}\right)$ have also been tested as a possible contributor to densification rate. A "stripe" scanning strategy has been chosen for the building of the different samples, with a constant hatch distance of $140 \mu \mathrm{m}$. For each specimen, three measurements have been performed. Results are presented in Table 3.

Table 3

Set of SLM Parameters and porosity ratios.

\begin{tabular}{|c|c|c|c|c|c|c|c|c|c|c|}
\hline & \multirow[t]{2}{*}{ Test } & \multirow[t]{2}{*}{$\theta\left({ }^{\circ}\right)$} & \multicolumn{3}{|c|}{ Contour parameters } & \multicolumn{3}{|c|}{ Hatching parameters } & \multirow{2}{*}{$\begin{array}{l}\text { VED (hatching) } \\
\mathrm{J} / \mathrm{mm}^{3}\end{array}$} & \multirow{2}{*}{$\begin{array}{l}\text { Porosity } \\
(\%)\end{array}$} \\
\hline & & & $\mathrm{P}(\mathrm{W})$ & $\mathrm{V}(\mathrm{m} / \mathrm{s})$ & $\mathrm{D}(\mu \mathrm{m})$ & $P(W)$ & $\mathrm{V}(\mathrm{m} / \mathrm{s})$ & $\mathrm{D}(\mu \mathrm{m})$ & & \\
\hline \multirow[t]{23}{*}{ Tests for porosity } & 7 & 0 & 400 & 1 & 70 & 400 & 1 & 70 & 104 & $0,51 \pm 0.05$ \\
\hline & 8 & 0 & 400 & 1.4 & 70 & 400 & 1.4 & 70 & 74.3 & $1,17 \pm 0.4$ \\
\hline & 9 & 0 & 400 & 1.8 & 70 & 400 & 1.8 & 70 & 57.8 & $1,85 \pm 0.34$ \\
\hline & 10 & 0 & 400 & 2 & 70 & 400 & 2 & 70 & 52 & $2,43 \pm 0.9$ \\
\hline & 11 & 0 & 400 & 1 & 160 & 400 & 1 & 160 & 19.9 & $0,36 \pm 0.09$ \\
\hline & 12 & 0 & 400 & 1.4 & 160 & 400 & 1.4 & 160 & 14.2 & $0,91 \pm 0.12$ \\
\hline & 13 & 0 & 400 & 1.8 & 160 & 400 & 1.8 & 160 & 11.1 & $2,96 \pm 0.8$ \\
\hline & 14 & 0 & 400 & 2 & 160 & 400 & 2 & 160 & 10 & $2,7 \pm 0.4$ \\
\hline & 15 & 0 & 400 & 1 & 240 & 400 & 1 & 240 & 8.8 & $1,16 \pm 0.09$ \\
\hline & 16 & 0 & 400 & 1.4 & 240 & 400 & 1.4 & 240 & 6.3 & $1,30 \pm 0.6$ \\
\hline & 17 & 0 & 400 & 1.8 & 240 & 400 & 1.8 & 240 & 5,1 & $5,06 \pm 0.2$ \\
\hline & 18 & 0 & 400 & 2 & 240 & 400 & 2 & 240 & 4,6 & $7,20 \pm 0.3$ \\
\hline & 19 & 0 & 180 & 0,5 & 70 & 175 & 0,6 & 70 & 79,3 & $1,44 \pm 0,4$ \\
\hline & 20 & 0 & 140 & 0,5 & 70 & 175 & 0,6 & 70 & 79,3 & $0,7 \pm 0,16$ \\
\hline & 21 & 0 & 140 & 0,5 & 70 & 175 & 0,7 & 70 & 68 & $1,29 \pm 0,22$ \\
\hline & 22 & 10 & 140 & 0.5 & 70 & 150 & 0.6 & 70 & 68 & $0.2 \pm 0.08$ \\
\hline & 23 & 10 & 140 & 0.5 & 70 & 200 & 0.6 & 70 & 90,7 & $0.37 \pm 0.18$ \\
\hline & 24 & 10 & 140 & 0.5 & 70 & 175 & 0.7 & 70 & 68 & $2.1 \pm 0.51$ \\
\hline & 25 & 10 & 140 & 0.5 & 70 & 175 & 0.8 & 70 & 59,5 & $6.32 \pm 1.26$ \\
\hline & 26 & 35 & 140 & 0.5 & 70 & 150 & 0.6 & 140 & 17 & $0.36 \pm 0.04$ \\
\hline & 27 & 35 & 140 & 0.5 & 70 & 200 & 0.6 & 140 & 22,6 & $0.12 \pm 0.02$ \\
\hline & 28 & 35 & 140 & 0.5 & 70 & 175 & 0.7 & 140 & 17 & $0.66 \pm 0.06$ \\
\hline & 29 & 35 & 140 & 0.5 & 70 & 175 & 0.8 & 140 & 14,8 & $1.61 \pm 0.30$ \\
\hline
\end{tabular}




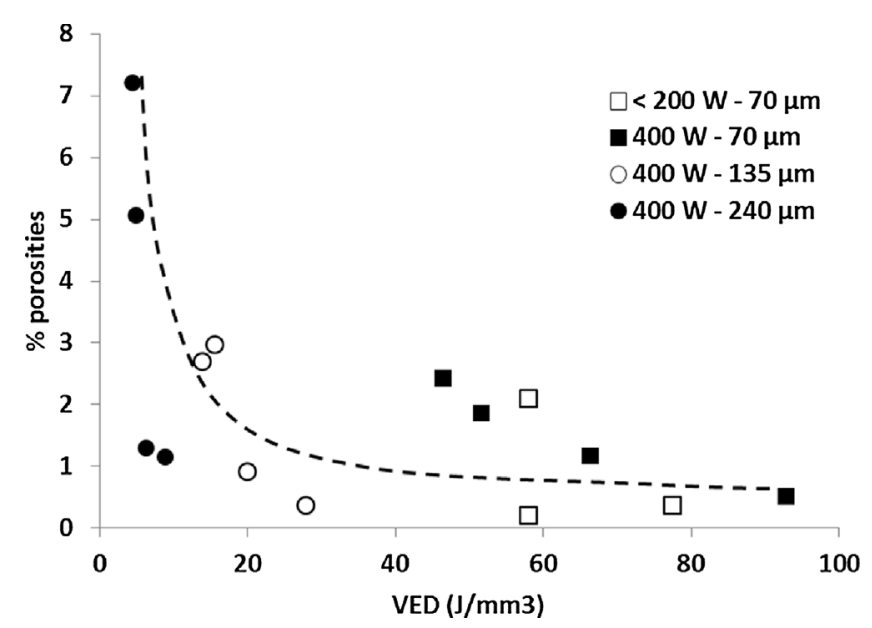

Fig. 9. Dependence of porosity content versus process parameters in In625 for $\mathrm{P}<200 \mathrm{~W}$ and $\mathrm{P}=400 \mathrm{~W}\left(10^{\circ}\right.$ angle).

For a constant building angle $\left(0^{\circ}\right)$, the results (Fig. 9) corresponding to specimens $7-21$ indicate that the mean porosity rate value globally decreases with VED values $\left(\mathrm{J} / \mathrm{mm}^{3}\right)$ above a VED threshold $(\approx 7 \mathrm{~J} /$ $\mathrm{mm}^{3}$ ). The main explanation is that high VED promote larger meltpools susceptible to better re-melt inter-layer porosities. For 3 different beam diameters, and various $(\mathrm{P}, \mathrm{V})$ values a similar evolution is shown with VED. Moreover, for all the (P, V, D) conditions considered, a correct densification (to less than $0.5 \%$ porosity rate) is shown above a similar VED threshold (close to $30-40 \mathrm{~J} / \mathrm{mm}^{3}$ ).

The inclination of parts (from 10 to $35^{\circ}$ ) has a clear effect on densification rates because higher inclinations increase average temperatures due to heat concentration in the lower sides of SLM walls (Fig. 10) for specimens 22-29. This explains why, in \% porosities versus VED curves the densification starts for 2 times lower VED on $35^{\circ}$ inclined parts (Fig. 10).

All these data globally tend to confirm the possibility to use VED as a rather reliable process parameter combining $\mathrm{P}, \mathrm{V}$ and $\mathrm{D}$, for a constant building angle $\theta$ and layer height $\Delta \mathrm{h}$.

However, the variation of laser beam spatial distribution with $\mathrm{z}$ defocusing may explain why the use of VED is not fully sufficient to predict porosity rate with a good accuracy for a large range of diameters (variations of the porosity rates are shown).

Finally, for optimized conditions, a $0.1-0.25 \%$ minimum porosity rate is achievable with SLM, to be compared with the values obtained by (Spierings et al., 2011) with SLM on a 316L stainless steel, which are comprised between 0.3 and $0.5 \%$. (Tang et al., 2017) has summarized

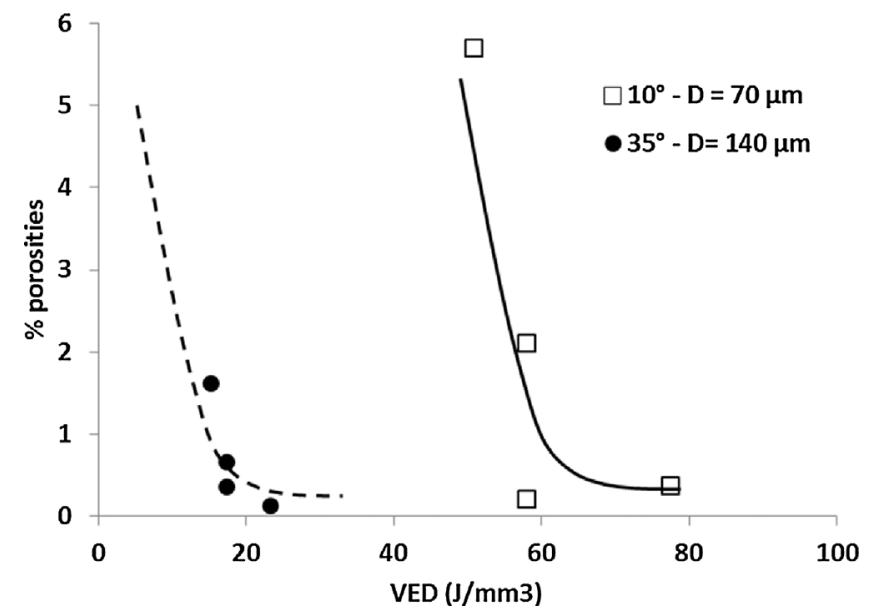

Fig. 10. Dependence of porosity content versus process parameters in In625 for two distinct building angles $\left(10^{\circ}\right.$ and $\left.35^{\circ}\right)$. different values of porosity rate for different material, which are comprised between 0.8 and $3 \%$, in order to propose a geometry based simulation to predict porosity caused by insufficent overlap of melt pools in powder bed fusion.

An interesting point to notice on cross-sections micrographs (Fig. 11) is the change of size and geometry of pores in the volume and close to the surface. Two different geometries of pores are clearly shown on cross-sections:

- In the sample volume, the geometry of pores is circular and their size is between 10 to $40 \mu \mathrm{m}$ ( $0.3 \%$ of porosity).

- Close to the surface of the specimen, their sphericity decreases and their mean diameter increases up to 150 and $200 \mu \mathrm{m}(2.2 \%$ of porosity). This last family of porosity can be explained by the overlap between the two strategies, (contour + hatching), or by decelerating-accelerating issues of the scan head near the contour, which favor deeper beads, and possible key-hole closure effects, similar to welding issues (Sames et al., 2016).

(Kasperovich et al., 2016) has done a similar study in a Ti6AlV4 produced by SLM with the effect of more parameters. The scan-strategy used is the zigzag scan vectors. They observed that the velocity exerts the most dominant influential parameter (with porosity between $0,1 \%$ at $125 \mathrm{~J} / \mathrm{mm}^{2}$ and $3,2 \%$ at $300 \mathrm{~J} / \mathrm{mm}^{2}$ ) as obtained in our study.

\section{Fatigue behavior of as-built and re-polished SLM samples}

The aim of this part is to better understand the fatigue mechanisms for parts manufactured by the SLM process. The originality of this study is to compare specimens with skin-process (as built SLM surface) and polished specimen (without skin-process), using a $220 \mathrm{SiC}$ paper resulting in a smoothing effect ( $\mathrm{Sa} \approx 0.8 \mu \mathrm{m}$ for polished samples compared with $7 \mu \mathrm{m}$ for the as-built condition).

\subsection{Selection of optimum SLM parameters}

Following process investigations carried out in the previous two parts, SLM parameters were chosen for manufacturing fatigue samples, mostly considering the reduction of porosity rate and surface finish which are both expected to be major contributors to fatigue crack initiation. For this reason, SLM parameters, corresponding to high VED values ( $93 \mathrm{~J} / \mathrm{mm}^{3}$ for the contour and $87 \mathrm{~J} / \mathrm{mm}^{3}$ for the hatching), and a low building angle $\left(10^{\circ}\right)$ were used (Table 4$)$.

\subsection{Tensile tests}

Prior to fatigue tests, two tensile tests were carried out under quasistatic load conditions $\left(10^{-3} \mathrm{~s}^{-1}\right)$ directly on as-built SLM samples with the orientation shown in Fig. 2. Results presented here below, are at least as good than previous ALM works on Inconel 625 (Table 1), despite the presence of $\approx 0.3 \%$ porosity rate (Table 5 ).

\subsection{Fatigue tests}

Seven fatigue tests were conducted to determine the number of cycles to failure for as-built and polished specimens, at different stress amplitudes (with a $25 \mathrm{MPa}$ increment). Even if the number of specimens is limited, the results and the failure surface obtained give important information and ways of improving SLM materials for fatigue applications.

All tests were carried out at a test frequency of $20 \mathrm{~Hz}$ with a load Rratio equal to -1 using the specimen geometry presented in Fig. 3 . Specimens that survived $2 \times 10^{6}$ cycles have been retested at a higher stress level, increased by $25 \mathrm{MPa}$, to estimate the fatigue strength and to observe the fatigue damage mechanism on the failure surfaces. The results are summarized in Table 6 and plotted as a S-N Wöhler curve 

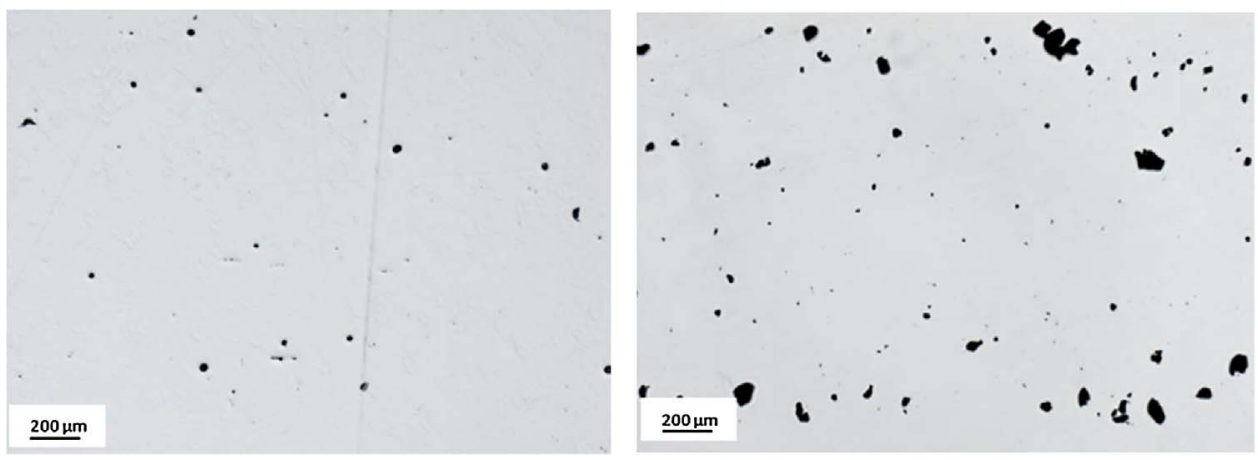

Fig. 11. 2D quantification of the voids fraction a) in the cross-section ( $0.3 \%$ of spherical porosities) b) close to the surface ( $2.2 \%$ of porosity) (sample 24 : $150 \mathrm{~W}-0.6 \mathrm{~m} / \mathrm{s}-10^{\circ}$ ).
Table 4

SLM Process parameters carried out on static tensile and fatigue samples.

\begin{tabular}{llllllll}
\hline$\theta\left({ }^{\circ}\right)$ & \multicolumn{2}{l}{ Contour parameters } & & & \multicolumn{3}{l}{ Hatching parameters } \\
\cline { 2 - 4 } \cline { 5 - 7 } & $\mathrm{P}(\mathrm{W})$ & $\mathrm{V}(\mathrm{m} / \mathrm{s})$ & $\mathrm{D}(\mu \mathrm{m})$ & & $\mathrm{P}(\mathrm{W})$ & $\mathrm{V}(\mathrm{m} / \mathrm{s})$ & $\mathrm{D}(\mu \mathrm{m})$ \\
\hline 10 & 180 & 0.5 & 70 & & 175 & 0.6 & 70 \\
\hline
\end{tabular}

Table 5

Results of tensile tests on as-built SLM samples.

\begin{tabular}{lllll}
\hline & E (GPa) & $\sigma_{\mathrm{Y}}(\mathrm{MPa})$ & A (\%) & UTS (MPa) \\
\hline Sample 1 & 177 & 711 & 35 & 976 \\
Sample 2 & 179 & 727 & 35 & 971 \\
\hline
\end{tabular}

(Fig. 12).

The estimated fatigue limits are between 175 and $200 \mathrm{MPa}$ (i.e. approximately $20 \%$ of the UTS). This is much lower than the fatigue strengths obtained with other manufacturing processes (Koutiri et al. 2013). Considering previous "SLM and fatigue" studies on other classes of materials, like an AlSI10Mg (Brandl et al., 2012) with a fatigue limit equal to approximately $30 \%$ of the UTS for the same building orientation, the fatigue strengths determined here can also be considered to be very low.

The fatigue results clearly indicate an increase in the number of cycles to failure (i.e. an average of approximately $+2 \times 10^{5}$ cycles for stress amplitudes of 225, 250 and $275 \mathrm{MPa}$ ) for the polished specimens, even if a higher difference could have been expected between the two conditions, due to the difference in surface roughness. However, for the same number of cycles, the difference in stress amplitude, observed between both conditions remains low. Despite the high surface roughness of as-built specimen, the difference in the fatigue strength between the polished and the as-built specimens is not pronounced (about 10\%).

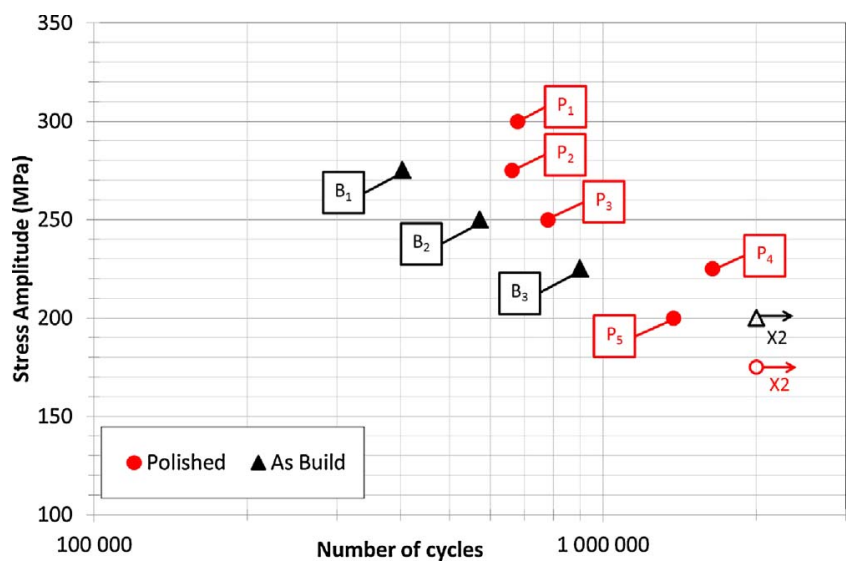

Fig. 12. S-N curves for polished and as-built batches.

This low difference can be explained by the similar defect size observed at the initiation sites for the two studied batches. This point is developed in next section.

\subsection{Analysis of failure mechanisms on SLM + re-polished specimens}

The failure surface of polished specimens has been observed using a Scanning Electron Microscopy (SEM) in order to address the fatigue mechanisms.

Observations of specimens $\mathrm{P}_{1}, \mathrm{P}_{6}$ and $\mathrm{P}_{4}$ (Fig. 13) show that the initiation of the fatigue crack occurs on sub-surface without any defects like inclusions or porosity at the initiation site. For these specimens, initiation is localized in the material matrix and is controlled by local plasticity, according to the less favorably crystal orientation (Dang Van, 1999). (Nicoletto, 2017) has observed the same mechanisms on smooth specimens in a Ti6Al4V obtained by powder bed laser fusion.

Table 6

Fatigue data, fully reversed tensile loads $(R=-1)$.

\begin{tabular}{|c|c|c|c|c|c|c|}
\hline \multicolumn{3}{|c|}{ Polished specimens } & \multicolumn{4}{|c|}{ As-built specimens } \\
\hline Specimen Name & $\sigma_{\mathrm{a}}(\mathrm{MPa})$ & $\mathrm{N}$ (cycles) & Specimen Name & $\sigma_{\mathrm{a}}(\mathrm{MPa})$ & N (cycles) & $\mathrm{Sa}(\mu \mathrm{m})$ \\
\hline $\mathrm{P}_{1}$ & 300 & 678663 & $\mathrm{~B}_{1}$ & 275 & $403887^{e}$ & 8.56 \\
\hline $\mathrm{P}_{2}$ & 275 & $662916^{p}$ & $\mathrm{~B}_{2}$ & 250 & $573095^{\mathrm{p}}$ & 9.85 \\
\hline $\mathrm{P}_{3}$ & 250 & $779395^{p}$ & $\mathrm{~B}_{3}$ & 225 & $901787^{\mathrm{e}}$ & 10.69 \\
\hline $\mathrm{P}_{4}$ & 225 & 1641598 & $\mathrm{~B}_{4}$ & 200 & 2000000 & 5.46 \\
\hline $\mathrm{P}_{5}$ & 200 & $1373450^{\mathrm{p}}$ & $\mathrm{B}_{4}$ & 225 & $1069045^{\mathrm{e}}$ & \\
\hline $\mathrm{P}_{6}$ & 175 & 2000000 & $\mathrm{~B}_{5}$ & 200 & 2000000 & 4.82 \\
\hline $\mathrm{P}_{6}$ & 200 & 1190074 & $\mathrm{~B}_{5}$ & 225 & 2000000 & \\
\hline $\mathrm{P}_{7}$ & 175 & 2000000 & $\mathrm{~B}_{5}$ & 250 & 355349 & \\
\hline $\mathrm{P}_{7}$ & 200 & $261270^{p}$ & & & & \\
\hline
\end{tabular}

\footnotetext{
${ }^{\mathrm{P}}$ initiation from a porosity.

e initiation from an embedded particle.
} 


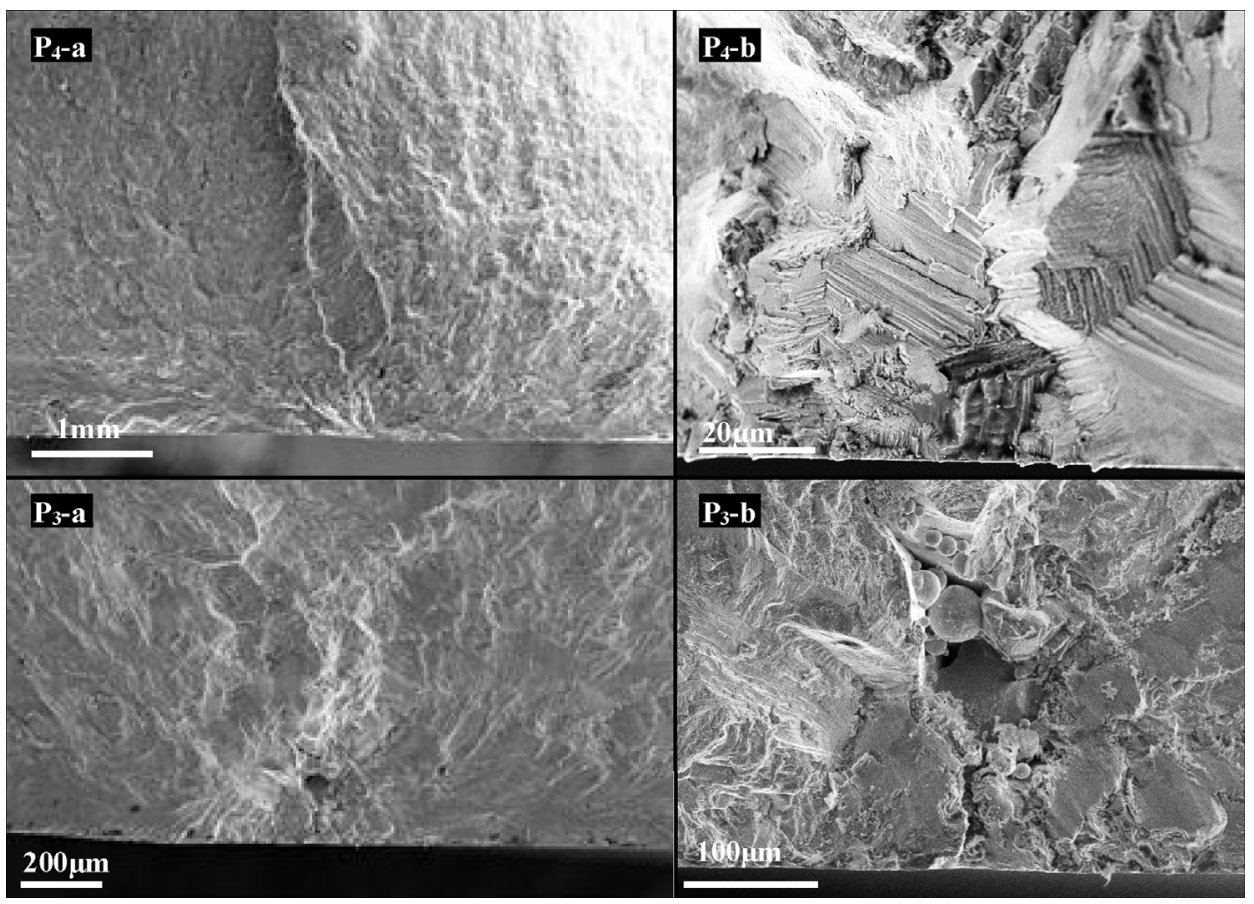

Fig. 13. SEM images of fracture surfaces showing the crack initiation location for the polished samples.

Other fatigue initiation mechanisms are observed in samples $\mathrm{P}_{2}, \mathrm{P}_{3}$, $\mathrm{P}_{5}$ and $\mathrm{P}_{7}$ where cracks initiate from pores created during the SLM process. In Fig. 13 (sample $\mathrm{P}_{3}$ ), a $60 \mu \mathrm{m}$ diameter pore is located at 150 microns below the surface. It is believed that the associated porosity (which is not fully spherical) can be correlated to the sub-surface pores shown in Fig. 13, and attributed to a key-hole like welding mode or a lack of inter-layer dilution. (Konecna et al., 2016) observed the same mechanism in an Inconel 718 on smooth specimens.

It is therefore concluded that fatigue damage in this material is controlled by two different fatigue mechanisms: one is associated with relatively large pores and the other is controlled by local plasticity within the material matrix.

\subsection{Failure mechanisms of as-built SLM specimens}

In order to characterize the fatigue mechanisms on specimens carried out with a skin ("contour") process, failure surfaces have also been observed on as-built SLM samples to explain the difference obtained with polished specimens.

The initiation site in specimen $\mathrm{B}_{2}$ is at a large pore in which some un-melted particle powder can be observed (see Fig. 14). This initiation mechanism is the same as that observed for the polished specimens $P_{2}$,
$\mathrm{P}_{3}, \mathrm{P}_{5}$ and $\mathrm{P}_{7}$. For the specimen $\mathrm{B}_{5}$ which has a particular high fatigue strength there are no pores observed at the initiation site, as per the polished specimens $\mathrm{P}_{1}, \mathrm{P}_{4}$ and $\mathrm{P}_{6}$.

The observations show that for specimens $B_{1}, B_{3}$, and $B_{4}$ a similar crack initiation mode occurs, controlled by the presence of large embedded particles, and localized on the surface of the specimen (Fig. 15 for specimen B1 and Fig. 16 for specimen B3). These particles have a diameter of about $150 \mu \mathrm{m}$ which seems large compare to the grain size distribution (Fig. 1). Spatter ejection, generated during the powder bed laser beam melting process, discussed in recent papers (Wang et al., 2017, Gunenthiram et al., 2018) could explain the origin of this kind of defect.

Specimen $B_{1}$ shows an unusual failure surface, in which a competition between two different heterogeneities can be observed (Fig. $15 \mathrm{~B}_{1}$ b) and $\left.B_{1}-c\right)$ ). This promotes the formation of two fatigue crack initiation sites (one at a sub-surface pore and the other at a $150 \mu \mathrm{m}$ embedded particle).

The specimen $B_{3}$ was analyzed in greater detail prior to and after fatigue testing. Prior to fatigue tests, a 3D surface scan was carried out to detect and visualize the position and the size of embedded particles. It can be seen in Fig. $15 \mathrm{~B}_{3}$-C that approximately twenty particles are present on the specimen surface. The critical defect can be identified on

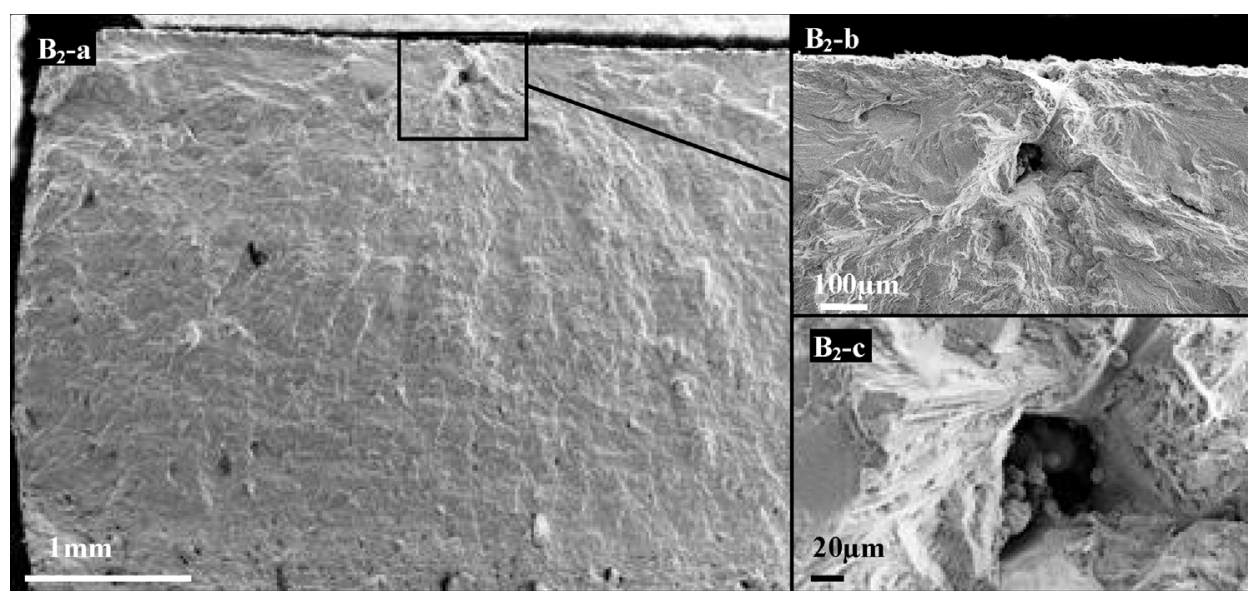

Fig. 14. SEM images of fracture surfaces showing the crack initiation location for the as-Built specimen B1. 


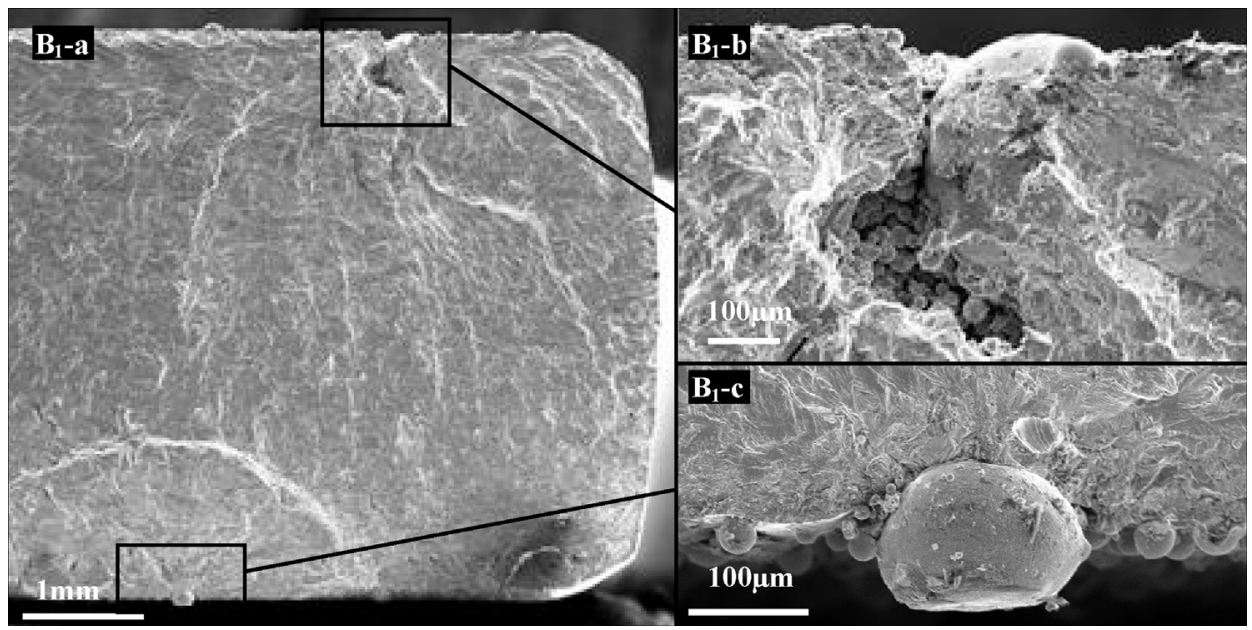

the surface scan using the fracture surface analysis. Fig. 15 shows the surface scan and a close-up of the critical defect of the as-built specimen $\mathrm{B}_{3}$.

On the failure surface, it can be observed that the interface between the particle and the material matrix is not completely smooth. A partially embedded particle seems to create an initial defect which could be very critical in fatigue. It can be observed in Fig. 16 that the 3D profilometer can be used to detect this kind of heterogeneity, as shown in Fig. $14 \mathrm{~B}_{3}-\mathrm{c} / \mathrm{d}$.

Finally, three different fatigue damage mechanisms are observed. The most damaging is probably due to particle ejected during the SLM process and embedded on the surface. The second one is controlled by the degree of porosity, created during the process close to the surface. The third and least damaging fatigue crack initiation mechanism observed is crack initiation due to local plasticity which appears in the material matrix.

These observations tend to show that the usual roughness parameters like Sa or St, which gives a more global description of the surface are probably not suitable to characterize the surface effect on fatigue. It seems to be more efficient to quantify and optimize the particle population in term of density, size or geometry in order to better assess the fatigue strength of a SLM material. New surface parameters must also be developed to propose a link between the surface state and the fatigue strength of this type of material.

\section{Conclusion and future work}

The SLM manufacturing of Inconel 625 samples has been carried out with a double objective: (1) determining optimum process parameters leading to reduced surface finish and porosity rate and understanding underlying physics, and (2) investigating the fatigue behavior and failure mechanisms on as-built and (as-built + re-polished) samples.

The first part was focused on parameters to deliver the best surface finish. It appears that the correlation between surface roughness, which depends mostly on surface temperatures achieved on SLM part, and process parameters, is not a simple task, and that the use of VED as a

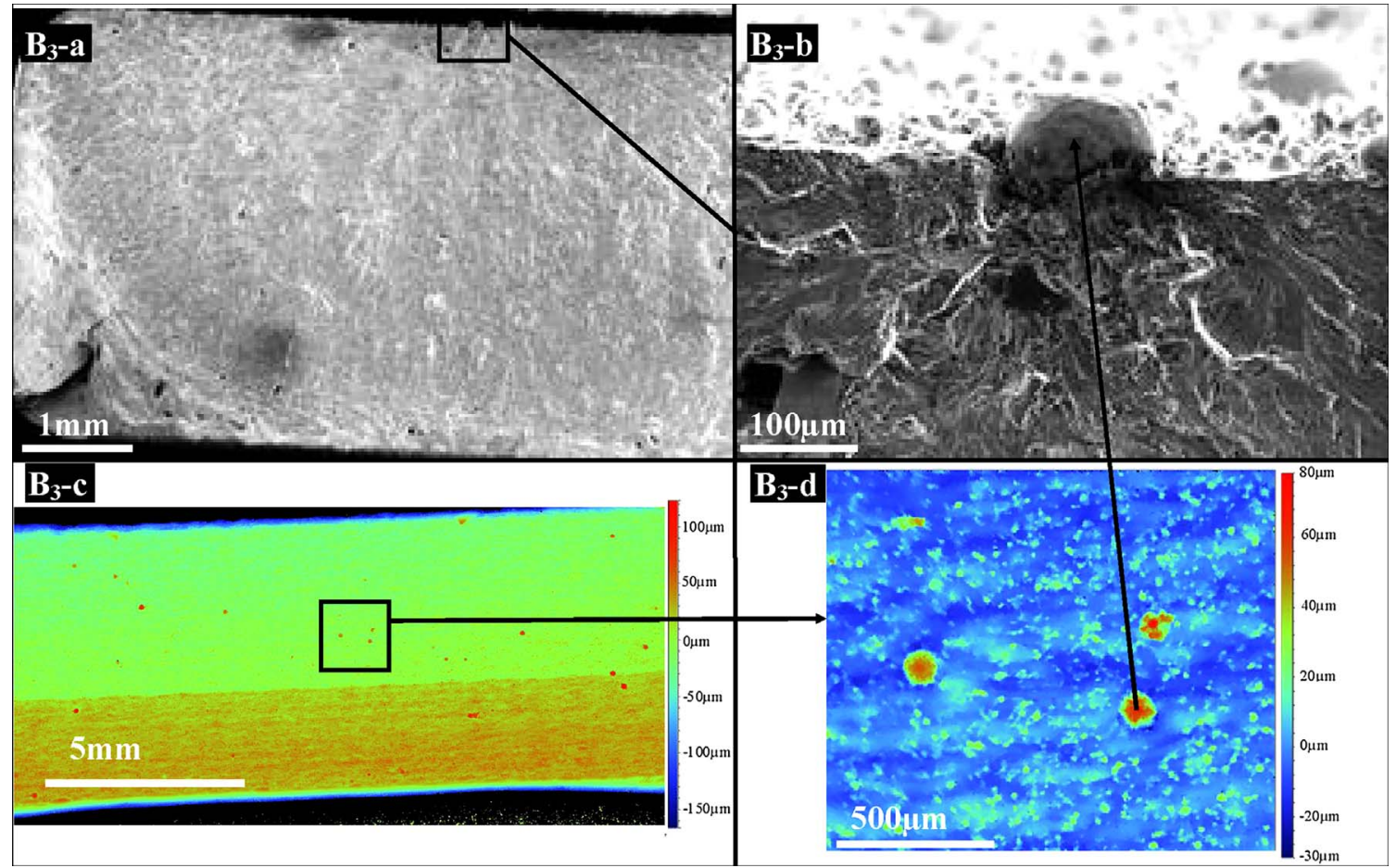

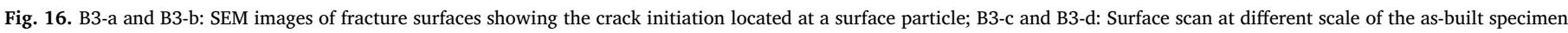
showing the critical particle at the origin of the failure initiation. 
representative factor is not fully satisfactory, especially when considering a large range of laser spot diameters. Globally, Sa was shown to increase with lower scan speeds, to decrease with higher powers, and to increase severely on down-skin sides for large building angles.

In a second part, hatching parameters have been optimized to reach an optimum densification state. For a constant building angle $\left(10^{\circ}\right)$, the porosity rate globally decreases with VED values $\left(\mathrm{J} / \mathrm{mm}^{3}\right)$ above a VED threshold. Logically, high enough VED promote large melt-pools susceptible to better re-melt inter-layer porosities. The inclination of parts (from 10 to $35^{\circ}$ ) also has a clear effect on densification rates because higher inclinations increase average temperatures due to heat concentration in the lower sides of SLM walls. Contrary to the surface roughness, the possibility to use VED as a rather reliable process parameter combining $\mathrm{P}, \mathrm{V}$ and $\mathrm{D}$, for a constant building angle $\theta$ and layer height $\Delta \mathrm{h}$ is confirmed.

Finally, this process optimization was found to be a compromise between an optimum densification state and a minimum number of contaminating spatters which degrade the surface roughness.

An experimental fatigue campaign has been conducted on as-built specimens and polished specimens. Despite the poor surface roughness of as-built specimen, the polished and the as-built fatigue batches exhibit similar fatigue strength. This can be explained by the defects associated with crack initiation sites which are similar in size for the studied specimens.

Three different fatigue damage mechanisms have been observed and described:

- Particles probably ejected during the SLM process, which stick to and become embedded on the surface.

- Porosity created during the SLM process, located on the surface or sub-surface of the material.

- Local plasticity which appears in the matrix material, depending on material microstructure.

This study provides an initial step for future modeling work to describe the fatigue behavior of as-built SLM specimens. For instance, in the future, a probabilistic approach using the weakest link concept (Pessard et al., 2011) could be introduced to model the competition between the three damage mode that have been observed.

\section{Acknowledgement}

This work was carried out under the framework of the PSPC project FAIR. Authors thank BPI for financial support.

\section{References}

Akita, M., Uematsu, Y., Kakiuchi, T., Nakajima, M., 2016. Defect-dominated fatigue behavior in type 630 stainless steel fabricated by selective laser melting. Mater. Sci.
Eng. A 666, 19-26.

Brandl, E., Heckenberg, U., Holzinger, V., Buchbinder, D., 2012. Additive manufactured AlSi10Mg samples using selective laser melting (SLM): microstructure, high cycle fatigue and fracture behavior. Mater. Des. 34, 159-169.

Chastanda, V., Tezenasa, A., Cadoreta, Y., Quaegebeurb, P., Wilson, M., Charkaluk, E. 2016. Fatigue characterisation of titanium Ti-6Al-4V samples produced by additive manufacturing. Procedia Struct. Integrity 2, 3168-3176.

Dang Van, K., 1999. Introduction to fatigue analysis in mechanical design by the multiscale. High Cycle Metal Fatigue CISM Courses and Lectures. SpringerWienNewYork.

Ellyson, B., Brochu, M., Brochu, M., 2017. Characterisation of bendig vibration fatigue of SLM fabricated Ti6Al4V. Int. J. Fatigue 99, 25-34.

Fabbro, R., Dal, M., Peyre, P., Coste, F., Schneider, M., Gunenthiram, V., 2017. Analysis and possible estimation of keyhole depths evolution using laser operating parameters and materials properties. Proceedings of ICALEO2017.

Fatemi, A., Molaei, R., Sharifimehr, S., Shamsaei, N., Phan, N., 2017. Torsional fatigue behavior of wrought and additive manufactured Ti6Al4V by powder bed fusion including surface finish effect. Int. J. Fatigue 99, 187-201.

Gunenthiram, V., Peyre, P., Schneider, M., Dal, M., Coste, F., Koutiri, I., Fabbro, R., 2018. Experimental analysis of spatter generation and melt-pool behavior during the powder bed laser beam melting process. J. Mater. Process. Technol. 376-386.

Kasperovich, G., Haubrich, J., Gussone, J., Requena, G., 2016. Correlation between porosity and processing parameters in TiAl6V4 produced by selective laser melting. Mater. Des. $160-170$.

Khairallah, S.A., Anderson, A.T., Rubrnvich, A., King, W.E., 2016. Laser powder bed fusion aditive manufacturing : physics of complex melt flow and formation mechanisms of pores, spatter and denudation zones. Acta Mater. 108, 36-45.

Konecna, R., Nicoletto, G., Kunz, L., Baca, A., 2016. Microstructure and directional fatigue behavior of Inconel 718 produced by selective laser melting. Procedia Struct. Integrity $2,2381-2388$.

Koutiri, I., Bellett, D., Morel, F., Pessard, E., 2013. A probabilistic model for the high cycle fatigue behaviour of cast aluminium alloys subject to complex loads. Int. J. Fatigue 47, 137-147.

Leary, M., 2017. Surface roughness optimisation for selective laser melting (SLM): accommodating relevant and irrelevant surfaces. Laser Addditve Manufacturing. pp. 99-118.

Nicoletto, G., 2017. Anisotropic high cycle fatigue behavior of Ti-6Al-4V obtained by powder bed laser fusion. Int. J. Fatigue 94.

Pessard, E., Morel, F., Morel, A., Bellett, D., 2011. Modelling the role of non metallic inclusions on the anisotropic fatigue behaviour of forged steel. Int. J. Fatigue 33, $568-577$.

Sames, J., List, F.A., Pannala, S., Dehoff, R.R., Babu, S.S., 2016. The metallurgy and processing science of metal additive manufacturing. International Materials Review.

Siddique, S., Imran, M., Walther, F., 2017. Very high cycle fatigue and fatigue crack propagation behavior of selective laser melted AlSi12 alloy. Int. J. Fatigue 94 246-254.

Spierings, A.B., Schneider, M., Eggenberger, R., 2011. Comparison of density measurement techniques for additive manufactured metallic parts. Rapid Prototyp. J. 380-386.

Tang, M., Chris Pistorius, P., Beuth, J.L., 2017. Prediction of lack-of fusion porosity for powder bed fusion. Addit. Manuf. 14, 39-48.

Triantaphyllou, A., Giusca, C.L., Macaulay, G.D., Roering, F., Hoebel, M., Leach, R.K., Tomkta, B., Milne, K.A., 2015. Surface texture measurement for additive manufacturing. Surf. Topogr. Metrol. Prop. 3, 1-8.

Wang, D., Wu, S., Fu, F., Mai, S., Yang, Y., Liu, Y., Song, C., 2017. Mechanisms and characteristics of spatter generation in SLM processing and its effect on the properties. Mater. Des. 121-130.

Wang, P., Zhang, B., Cheh Tan, C., Raghavan, S., Lim, Y.-F., Sun, C.-N., Wei, J., Chi, D., 2016. Microstructural characteristics and mechanical properties of carbon nanotube reinforced inconel 625 parts fabricated by SLM. Mater. Des. 112, 290-299.

Yadroitsev, I., Thivillon, L., Ph, Bertrand, Smurov, I., 2007. Strategy of manufacturing components with designed internal structure by selective laser melting of metallic powder. Appl. Surf. Sci. 254, 980-983. 